\title{
Organizational Contexts, Team Designs and Process Variables as Factors Influencing Team Effectiveness
}

\author{
Kay Dora Abd Ghani (Corresponding author) \\ Faculty of Civil Engineering, Universiti Teknologi MARA \\ 02600 Arau, Perlis, Malaysia \\ Tel: 60-9-988-2745Ｅ-mail: kaydora@perlis.uitm.edu.my \\ Sheikh Ahmad Izaddin Sheikh Mohd Ghazali \\ Faculty of Applied Sciences, Universiti Teknologi MARA \\ 72000 Kuala Pilah, Negeri Sembilan, Malaysia \\ E-mail: sheikhahmadizaddin@ns.uitm.edu.my
}

Mohammad Ismail

Faculty of Business Management, Universiti Teknologi MARA

02600 Arau, Perlis, Malaysia

E-mail: mohammadismail@perlis.uitm.edu.my

Mohd Subri Tahir

Department of Business Management, Universiti Teknologi MARA

13500 Permatang Pauh, Pulau Pinang, Malaysia

E-mail: subri@ppinang.uitm.edu.my

\begin{abstract}
Much has been said and written about the importance of teams to the success of the organizations and emphasis has been given to the benefits of team-building activities to achieving both team and organizational effectiveness. A lot of research describes attempts to move beyond team building and to link organizational development to team effectiveness in a coherent way. There is vast literature which addresses the topic on team effectiveness. The purpose of this paper is to investigate the team effectiveness factors which focus on the organizational contexts, team design and process variables, within a manufacturing company involved in cement industry. The result indicates that these three independent variables are major contributors to the team effectiveness.
\end{abstract}

Keywords: Influence factors, Organizational contexts, Team designs, Process variables, Team effectiveness

\section{Introduction}

The word "team" can be defined as a reasonably small group of people, who bring to the table a set of complementary and appropriate skills, and who hold themselves mutually accountable for achieving a clear and identifiable set of goals (Hick, 1999). In many organizations, employees who are organized into progressively larger groups of teams and departments work together toward the achievement of organizational goals and objectives. There are several types of teams, for instance functional teams, cross-functional teams, problem solving teams, self-managed work teams and so on but the concept is still the same even though they might be differences in terms of its types.

A team is said to be effective if the measured output is meet or beyond expectations. However, producing quality output is not enough to judge the effectiveness of the team. There are also other criteria to be considered such as the team 
should still be able to position effectively after it has accomplished its task, the team should not be torn apart by dissension after the team has been disbanded and the team members should have an enhanced working relationship that benefits the organization. Finally, effectiveness is measured by whether the teams experience satisfaction in performing their roles and if the team members are satisfied with their efforts, then the experience has been a worthy and the team has likely been effective.

Most of the top management of any company continuously encourage employees at all levels to work in teams and nurture the culture of working teams by using work teams as the basic unit of organization. Hence problem solving teams are used to improve the way the organization performs, and management teams are used to develop strategies and drive the changes. Teams can have their shady side and sometimes could be ineffective and highly dysfunctional. Theoretically, forming a team is much easier than ensuring it runs effectively with good coordination and solid cooperation implemented by team members as each employee has a unique personality and a different point of view. It is not easy to come out with a consensus in decision making. Consequently, bad decisions-making will lead to conflict among the team members. Since teamwork is viewed as an important aspect of organizational success, it is practically important to determine ways to enhance team effectiveness.

Thus, this study is carried out to investigate the link between team effectiveness and the three imperative factors such as organizational contexts, team design and processes, within the manufacturing company involved in cement industries in the Northern Region of Peninsular Malaysia.

To be specific, this research attempts to give academic insight into the link between team effectiveness and the three aspects; organizational contexts, team design and processes variables and will attempt to underline the importance thereof with current results. The problem that is investigated therefore revolves around the specific factors to be considered in creating team effectiveness in an organization. Therefore, the research questions of this study are:

Do organizational contexts affect team effectiveness?

Do team designs affect team effectiveness?

Do process variables affect team effectiveness?

\section{Literature review}

\subsection{Previous studies on the relationship of team effectiveness, organizational contexts, team designs and process} variables

There is vast literature which addresses the definition on the team effectiveness. For example, Shane and Glinow (2002) defined team effectiveness as the extent to which a team achieves its objectives, achieves the needs and objectives of its members and sustains itself over time. A team is effective when all members are satisfied with the system and able to maintain the commitment of its members, particularly during the turbulence of the team's development. Without this commitment, people leave and the team will fall apart. In this study, the researchers adopt the definition of team effectiveness as defined by Shane and Glinow (2002).

To measure the effectiveness of a team, this study considers three variables such as organizational contexts, team design and process variables.

The organizational context that surrounds a team has been identified by researchers as an important consideration in the study of work team effectiveness. Shane and Glinow (2002) have presented a model of team effectiveness by looking at organizational and team environment factors that include reward systems, communication systems, physical space, organizational environment, organizational structure and organizational leadership. However, according to Robbins (2005), the four organizational contexts that appear to be most significantly related to team performance are the presence of adequate resources, effective leadership, a climate of trust and a performance evaluation and reward system that reflect team contributions. Doolen, Hacker and Aken (2003) in their study entitled "The Impact of Organizational Context on Work Team Effectiveness: A Study of Production Team" was explores the relationships between nine organizational context variables, team processes, and three measures of team effectiveness. Organizational systems that provide teams with the necessary information were found to have a significant and positive linear relationship with both team leader ratings of effectiveness and team member satisfaction.

Besides organizational contexts, team design is also one of the variables considered in this study. According to Robbins (2005) effective teams need to work together and take collective responsibility to complete significant tasks. They must be more than a "team in name only." The work design category includes variables like freedom and autonomy, the opportunity to use different skills and talents (skill variety), the ability to complete a whole and identifiable task or product (task identity), and working on a task or project that has a substantial impact on others (task significance). Evidence indicates that these characteristics enhance member motivation and increase team effectiveness. Shane and Glinow (2002) stated that split team designs into two factors which are team composition and work design. The elements of team composition include abilities of members, personality, allocating roles, diversity, and size of teams, 
member flexibility and member preferences. The elements of work designs are autonomy, skill variety, task identity and task significance. Higgs, Plewnia and Ploch (2005) found in their study titled "Influence of Team Composition and Task Complexity on Team Performance" that there is a clear relationship between team composition (diversity), complexity of task and team performance. The design of their study is based on team diversity which was operational using the Belbin Team Role model. Diversity was found to be positively related to performance for complex tasks and negatively related for straightforward tasks.

The final category related to team effectiveness is process variable. According to Robbins (2005), these process variables include member commitment to a common purpose, establishment of specific team goals, team efficacy, and a managed level of conflict and minimized social loafing. Shane and Glinow (2002) found that elements of team process are team development, team norms, team roles and team cohesiveness. Janetta and Lisa (2001) indicated that items in the categories team outcomes, team goals and team cohesion were ranked most critical to team effectiveness. However, Dreu and Weingart (2003) found in their study entitled "Task Versus Relationship Conflict, Team Performance, and Team Member Satisfaction: A Meta-Analysis, conflict has stronger negative relations with team performance in highly complex (decision making, project, mixed) than in less complex (production) tasks. Lastly, task conflict was less negatively related to team performance when task conflict and relationship conflict were weakly, rather than strongly, correlated. Their study provides a meta-analysis of research on the association between relationship conflict, task conflict, team performance, and team member satisfaction. Consistent with past theorizing, results revealed strong and negative correlations between relationship conflict, team performance, and team member satisfaction. In contrast to what has been suggested in both academic research and introductory textbooks, however, results also revealed strong and negative (instead of the predicted positive) correlations between task conflict, team performance, and team member satisfaction.

In the literature review, the researchers have listed definitions of these three concepts of organizational contexts, team design and process variables as given by various researchers. Therefore, for the purpose of this study, organizational contexts can be defined as factors that include reward systems, communication systems, physical space, organizational environment, organizational structure and organizational leadership (Shane and Glinow, 2002); team designs can be defined as the recognition of the opportunity to use different skills and talents, the ability to complete a whole and identifiable task or product, and working on a task or project that has a substantial impact on others (Robbins, 2005); and finally the process variables can be defined as incorporating member commitment to a common purpose, establishment of specific team goals, team efficacy, and a managed level of conflict and minimized social loafing (Robbins, 2005).

\subsubsection{Research hypotheses}

$\mathrm{H}_{1}$ : There is a significant relationship between organizational contexts and team effectiveness

$\mathrm{H}_{2}$ : There is a significant relationship between team designs and team effectiveness

$\mathrm{H}_{3}$ : There is a significant relationship between process variables and team effectiveness

\section{Research methodology}

This is a descriptive study undertaken to identify the factors that contribute to team effectiveness among employees at a manufacturing company involved in cement industry in Perlis. Information that researchers get from the study were concerned about the relationship between organizational contexts, team designs and process variables with the team effectiveness. Questionnaires were distributed to the respondents which were the employees from 13 departments. The questionnaire method was chosen because a large sample could be targeted. The questionnaire used five-point Likert Scale ranging from strongly agrees to strongly disagree to measure each variable. Each item in the variable was measured from a range of 1-representing extremely dissatisfied to 5-representing extremely satisfied. A set of questionnaire consists of five sections. Section A consists of personal background or demographic questions which are employee's general information such as gender, age, marital status, length of services, educational background and others. Section B touches on the first independent variable which is the organizational context. As for Section C, it focuses on the second variable which is the team design. Section D consists of the third variable which represents the process variable. The last section is section $\mathrm{E}$ that represents the dependent variable which is team effectiveness. The researchers used probability sampling techniques in which every member of the population was known. It was based on random selection by the researcher. This research involved sample of 220 employees. Therefore, the researchers intended to use 140 of all the employees from 13 departments, consists all levels of workers at the manufacturing company as a sample size. However, only 57 respondents completed the questionnaire given. The Statistical Package for Social Science (SPSS) version 13 for windows was used to analyze information gathered in organizing and analyzing the data. Descriptive analysis was used to obtain frequency distribution, mean, median, maximum and standard deviation. Cronbach's alpha coefficient was also obtained to indicate how well the items in a set are positively correlated to one another. Finally, the data was tested and analyzed using the Multiple Regression Analysis with hypothesis testing. 


\section{Results and discussion}

The result of the study indicated that the highest respondents were males at the percentage of $63.20 \%$ represented by 36 respondents. The female respondents made up $36.80 \%$ which represented 21 respondents. Fourteen percent or 8 respondents from the total number of respondent represented the Electrical and Mechanical Departments; $12.30 \%$ or 7 respondents from the Finance and Human Resource Department; 5 respondents (8.80\%) each from ICT and Purchasing Departments; Kiln, Material Handling and Cement Mill and Packing Plants Department 5.30\% which was 3 respondents; and for the Corporate Communication; Safety and Health; Quarry and Engineering Services; and Internal Audit Departments represented 3.50\% which was 2 respondents respectively. The respondent age mostly were below 29 years old $(49.10 \%, 28$ respondents); age $30-39$ years old $(29.80 \%, 17$ respondents); age $40-49(15.80 \%, 9$ respondents) and above 50 years old (5.30\%, 3 respondents), including $87.70 \%$ (50 respondents) Malay, 10.50\% (6 respondents) Chinese; and $1.80 \%$ (1 respondent) Indian. 29 out of 57 respondents were single, followed by 27 respondents who were married. This represented $50.90 \%$ and $47.40 \%$ respectively. Only $1.80 \%$ represented 1 respondent who was divorced. 28 respondents $(49.10 \%)$ had less than 3 years of serving and 19 respondents $(33.30 \%)$ had serviced for more than 12 years. Most of the respondents (42.10\%, 24 respondents) had High School Certificate qualification.

The Cronbach's Alpha testing on instrument reliability coefficient from 0.65 to 0.87 showed that the data collected are reliable because the value of Cronbach's Alpha for the independent variables (organizational contexts, team designs, and process variables) were above 0.60 . It means the independent variables in this study were acceptable and all the items in a set were positively correlated to one another (Sekaran, 2000). As such the data collected does not shows any biasness and it is reliable for the follow up testing and the results are also expected to be reliable.

Table 1 presents the minimum, maximum, mean and standard deviation of the study variables - team effectiveness, organizational contexts, team designs and process variables. The number of cases in the dataset is recorded under the column labelled N. Information about the range of variables is given in the Minimum and Maximum columns. From the above table, the minimum number of respondents' answers for the dependent variable which is team effectiveness is 2.60. Some respondent felt that the team is not effective. As for the independent variables - organizational contexts, a minimum of 1.40 indicates that some of the respondents had strongly disagreed that the organizational contexts at the workplace may contribute to team effectiveness. A minimum of 3.60 for the independent variable - team designs indicates that the respondents were not sure regarding this variable but most chose "agree" with the way designing the team may affect the effectiveness of the team. The minimum of process variable is 2.60 which showed that some respondents had disagreed with the questions. Then, from the table, the researcher can conclude that the maximum of these 4 variables are 5.00 which are strongly agreed. The average answer is contained in the Mean column. The mean for the team effectiveness is 4.16, organizational contexts (3.98), team design (4.24) and process variable (3.98).

Variability can be assessed by examining the values in the Standard Deviation column. The Standard Deviation measures the amount of variability in the distribution of a variable. Thus, the more the individual data points differ from each other, the larger the standard deviation will be. Conversely, if there is a great deal of similarity between data points, the standard deviation will be quite small. The standard deviation describes how much the standard amount variables differ from the mean. The standard deviation for team effectiveness is .53, organizational contexts (.59), team design (.34) and process variable (.42).

\subsection{Pearson correlation}

The inferential statistic used to analyze the correlations between variables in this study. For this purpose, the Pearson Correlation was conducted to see how variables are related to one another and to indicate the direction, strength and significance of bivariate relationship of all the variables. Table 2 shows a correlation matrix with three numbers for each correlation. The correlation between team designs and team effectiveness in this study was $(r=.77, p<.01)$ which represent strong relationship. The team designs shows the strongest relationship followed by process variables $(\mathrm{r}=.75$, $\mathrm{p}<.01)$ and organizational contexts $(\mathrm{r}=.68, \mathrm{p}<.01)$. From the table, the researcher can conclude that all the three independent variables are predicted to be significantly positively correlated to team effectiveness. The team effectiveness is high if organizational contexts, team designs and process variables are high.

\subsection{Hypotheses testing}

Table 3 shows the result from the regression analysis in the SPSS. The value indicates that $74.7 \%$ of the variance in team effectiveness can be predicted from the variables of organizational contexts, team designs and process variables. The adjusted R-square attempts to yield a more honest value to estimate the R-squared for the population. The value of R-square was .747, while the value of Adjusted R-square was .73. Based on Table 5.3, all the three independent variables; organizational contexts $(\beta=.30, \mathrm{p}<.001)$, team designs $(\beta=.69, \mathrm{p}<.001)$ and process variables $(\beta=.33, \mathrm{p}$ $<.01)$ are significant and positively related to team effectiveness. Hence, $\mathrm{H}_{1}, \mathrm{H}_{2}$ and $\mathrm{H}_{3}$ are all supported.

The overall findings showed that there are relationship between organizational contexts, team designs and process 
variables with team effectiveness among employees at a manufacturing company involved cement industries in the Northern Region of Peninsular Malaysia. After analyzing of these three factors that influence team effectiveness, this study revealed that all three independent variables may increase team effectiveness.

Thus, from the aspect of organizational contexts in this manufacturing organization, the teams are part of the larger organization system. All teams rely on resources inside and outside the group to sustain it and a scarcity of resources directly reduce the ability of the team to perform its job effectively. One of the most important characteristics of an effective team is the support it receives from the organization. This support includes timely information, proper equipment, adequate staffing, encouragement and administrative assistance. A team must receive the necessary support from management and the larger organization if it is going to succeed in achieving its goals. Besides, team members must agree on who is to do what and ensure that all members contribute equally in sharing the workload. In addition, the team needs to determine how schedules will be set, what skills need to be developed, how the group will resolve conflicts and how the group will make and modify decisions; and agreeing on the specifics of work and how they fit together to integrate individual skills require team leadership and structure. Furthermore, members of effective teams should trust each other, and they also exhibit trust in their leaders. Interpersonal trust among team members facilitates cooperation, reduces the need to monitor each others' behavior, and bonds members around the belief that others on the team won't take advantage of them. Team members, for instance, are more likely to take risks and expose vulnerabilities when they believe they can trust others on their team.

From the aspect of team designs, for this manufacturing company, heterogeneous teams are more likely to have diverse abilities and information. While diverse teams may have more conflicts, they still tend to outperform homogeneous teams. When teams have exceeded 10 members, cohesiveness and mutual accountability declines, social loafing increases, and more people do less talking compared with others. So, in designing effective teams, managers should try to keep them to fewer than 10 .

Finally, for the process variables factor, effective teams have a common and meaningful purpose that provides direction, momentum and commitment for members. These specific goals facilitate clear communication and help teams maintain their focus on getting results. Members of successful teams put a tremendous amount of time and effort into discussing, shaping and agreeing on a purpose that belongs to them both collectively and individually. In addition, managers should consider providing training to improve members' technical and interpersonal skills. The greater the abilities of team members, the greater the likelihood that the team will develop confidence and the capability to deliver their abilities based on the confidence.

\section{Conclusion}

The findings of this study revealed that all three independent variables (organizational contexts, team designs and process variables) may increase team effectiveness at a manufacturing organization.

This study contributes to the existing literature in several ways. First, this study extends beyond previous research by investigating the effects of organizational contexts, team designs and process variables. This study will benefit the manufacturing company by providing them a better understanding on the factors that contribute to team effectiveness among its employees. The second contribution of the study is that, the use of various factors of the predictors will permit identification of which types of predictors affect highly the team effectiveness also provide practical value for managers in formulating effective teams. A further contribution of this study is that this study will also contribute to current literature on the team effectiveness. Thus, enrich the present knowledge and understanding on the building of an effective team.

\section{References}

Doolen, T. L., Hacker, M. E. \& Van Aken, E. M. (2003). The impact of organizational context on work team effectiveness: a study of production team, 50(3), 285-296.

Dreu, D. C. K. W. \& Weingart, L. R. (2003). Task versus relationship conflict, team performance and team member satisfaction: a meta-analysis, 88(42), 741-749.

Hick, M. (1999). Organizational behavior (2 ${ }^{\text {nd }}$ ed.). New York: McGraw Hill.

Higgs, M., Plewnia, U., \& Ploch, J. (2005). Influence of team composition and task complexity on team performance, 11(7/8), 227-250.

Janetta, L. F. \& Lisa E. M. (2001). Process variables critical for team effectiveness, 22(3), 158.

Robbins, S. P. (2005). Essentials of organizational behavior ( $8^{\text {th }}$ ed.). New Jersey: Prentice Hall.

Sekaran, U. (2000). Research methods for business: A skill-building approach, $3^{\text {rd }}$ ed. New York: Wiley.

Shane, M.S.L., \& Glinow, V.M. A. (2003). Organizational behavior ( $2^{\text {nd }}$ ed.). New York: McGraw Hill. 
Table 1. The descriptive statistics

\begin{tabular}{|l|c|c|c|c|c|}
\hline \multicolumn{1}{|c|}{ Variables } & $\mathrm{N}$ & Min & Max & Mean & $\begin{array}{c}\text { Standard } \\
\text { Deviation }\end{array}$ \\
\hline Team effectiveness & 57 & 2.60 & 5.00 & 4.16 & .53 \\
\hline Organizational Contexts & 57 & 1.40 & 5.00 & 3.98 & .59 \\
\hline Team Designs & 57 & 3.60 & 5.00 & 4.24 & .34 \\
\hline Process Variables & 57 & 2.60 & 5.00 & 3.98 & .42 \\
\hline
\end{tabular}

Table 2. Pearson correlation

\begin{tabular}{|c|c|c|c|c|c|}
\hline & & $\begin{array}{r}\text { Total score } \\
\mathrm{dv}\end{array}$ & $\begin{array}{r}\text { Total score } \\
\text { iv1 }\end{array}$ & $\begin{array}{r}\text { Total score } \\
\text { iv2 }\end{array}$ & $\begin{array}{r}\text { Total score } \\
\text { iv3 }\end{array}$ \\
\hline \multirow[t]{3}{*}{ Total score dv } & Pearson Correlation & 1 & & & \\
\hline & Sig. (2-tailed) & & & & \\
\hline & $\mathrm{N}$ & 57 & & & \\
\hline \multirow[t]{3}{*}{ Total score iv1 } & Pearson Correlation & $.68 * *$ & 1 & & \\
\hline & Sig. (2-tailed) & .00 & & & \\
\hline & $\mathrm{N}$ & 57 & 57 & & \\
\hline \multirow[t]{3}{*}{ Total score iv2 } & Pearson Correlation & $.77 * *$ & $.46 * *$ & 1 & \\
\hline & Sig. (2-tailed) & .00 & .00 & & \\
\hline & $\mathrm{N}$ & 57 & 57 & 57 & \\
\hline \multirow[t]{3}{*}{ Total score iv3 } & Pearson Correlation & $.75^{* *}$ & $.58 * *$ & $.70 * *$ & 1 \\
\hline & Sig. (2-tailed) & .00 & .00 & .00 & \\
\hline & $\mathrm{N}$ & 57 & 57 & 57 & 57 \\
\hline
\end{tabular}

Table 3. Multiple regressions analysis

\begin{tabular}{|l|l|l|}
\hline Independent Variables, iv & Standardized $\beta$ Coefficients & Sig. \\
\hline (Constant) & -1.23 & \\
\hline Organizational Contexts & .30 & .00 \\
\hline Team Designs & .69 & .00 \\
\hline Process Variables & .33 & .02 \\
\hline
\end{tabular}

Dependent variable: Team Effectiveness

$\mathrm{N}=57$

R Square $=.747$

Adjusted R Square $=.733$

$\mathrm{F}$ Value $=52.153 * *$ 